\title{
Seasonal and annual variations in the strength of the atmospheric electric field in the 24th cycle of solar activity measured in Yakutsk
}

\author{
Anatoliy Toropov ${ }^{1, *}$, Vladimir Kozlov ${ }^{1}$, Rustam Karimov ${ }^{l}$ \\ ${ }^{1}$ Yu.G. Shafer Institute of Cosmophysical Research and Aeronomy SB RAS, Yakutsk, Russia
}

\begin{abstract}
The paper presents the results of measuring the strength of the atmospheric electric field in fair weather conditions in the 24th cycle of solar activity from 2009 to 2019 according to observations in Yakutsk (North-east of Siberia). Intensity of the atmospheric electric field measurements by an electric field-mill sensor, mounted on the roof of the main building of the SchICRA SB RAS (N $62^{\circ} 11^{\prime}$, E129 ${ }^{\circ} 43^{\prime}$ ) in Yakutsk. The field-mill sensor has a measurement range of the atmospheric electric field strength $+/-50 \mathrm{kV} / \mathrm{m}$ with an accuracy of $+/-1 \mathrm{~V} / \mathrm{m}$. The data acquisition system based on a personal computer and an analog-to-digital converter (ADC) E 14-440 L-Card. Data is written to the hard disc drive of the data acquisition system with a one second resolution data. Based on the analysis of data on the atmospheric electric field from 2009 to 2019 it was found that the seasonal variation of the monthly mean values of the field strength has maxima in the spring and autumn months and minima in the summer and winter months. Annual variations of the field strength in fair weather conditions over the observation period have a general trend towards a decrease in the field strength.
\end{abstract}

\section{Introduction}

The problem of the appearance of an electric field in the Earth's atmosphere is one of the fundamental problems of atmospheric physics [1], which has not yet been resolved. The most recognized, at the present time, the theory that unites all electrical processes occurring in the atmosphere into a single current loop, and explains the appearance of the atmospheric electric field, is the concept of the global electrical circuit (GEC) [2,3]

According to modern concepts, the global electrical circuit covers the space from the Earth's surface to its magnetosphere and is a distributed electrical circuit on a planetary scale. The global electrical circuit is influenced by physical processes of terrestrial (mainly atmospheric) origin (high-altitude discharges to the mesosphere, etc.) and extraterrestrial (flows of charged particles from the sun, galactic cosmic rays, solar flares, etc.). Experimental studies of the atmospheric electric field make it possible to get closer to understanding the physical mechanisms underlying the global electric circuit, which is of considerable scientific and practical interest.

\footnotetext{
* Corresponding author: anatoliy.a.toropov@gmail.com
} 
In this article, we report on the results of a study of the strength of the atmospheric electric field in the period from 2009 to 2019 , covering the 24th cycle of solar activity.

\section{Equipment}

We use an electric field-mill sensor to measure the strength of the atmospheric electric field. The device has a field strength measurement range of $+/-50 \mathrm{kV} / \mathrm{m}$ with an accuracy of $+/-1 \mathrm{~V} / \mathrm{m}$. The data acquisition system based on a personal computer and an analog-todigital converter (ADC) E 14-440 L-Card. For the collection and primary processing of data, we used software written in the LabView language (National Instruments) using standard dynamic libraries (.dll) provided by the ADC manufacturer. Data is written to the file once per second. Transmission data between the electric field-mill sensor and the data acquisition system is via a shielded cable. Synchronization of the system time on the computer is carried out using standard time correction programs via the Internet. In the event of a power outage, the complex, using the battery of the uninterruptible power supply unit, remains operational for at least 2 hours.

Several times a year (during maintenance work), the electric field-mill sensor is calibrated in an artificial electric field. The electric field-mill sensor is located at the observation point, on the building of the Space Research Institute in Yakutsk (61 ${ }^{\circ} 59$ 'N, $129^{\circ} 41^{\prime} \mathrm{E}, 101$ meters above sea level) and has been in operation since 2008. This station is part of a network of EFM sensors installed in North-east of Siberia [4].

\section{Experimental data and results}

To obtain seasonal and annual variations in the electric field, we selected days with fair weather conditions (no precipitation, strong wind, fog, thunderstorms, etc.) for all months of the year from 2009 to 2019. Depending on the year, season and month, the number of selected days varied from 2 to 23 per month. It should be clarified that this sample did not include days during which observations were not made - electric field-mill sensor was turned off or did not function for a full day for various reasons (maintenance work, calibration, power outages, etc.).

Figure 1 shows a graph of seasonal variations in the electric field strength for each observation year from 2009 to 2019. The graph shows the monthly mean values of the atmospheric electric field strength. The seasonal variation of the field strength has maximums in the spring and autumn months and minimums in the summer and winter months. According to the literature [5], seasonal variations usually show only one minimum - in the summer months, while in winter, on the contrary, an increase in the field strength is observed. In our case, a winter minimum is observed (Figure 1), which we associate with a decrease in the field strength during winter frost (ice) fogs at the observation point as shown earlier in [6]. 


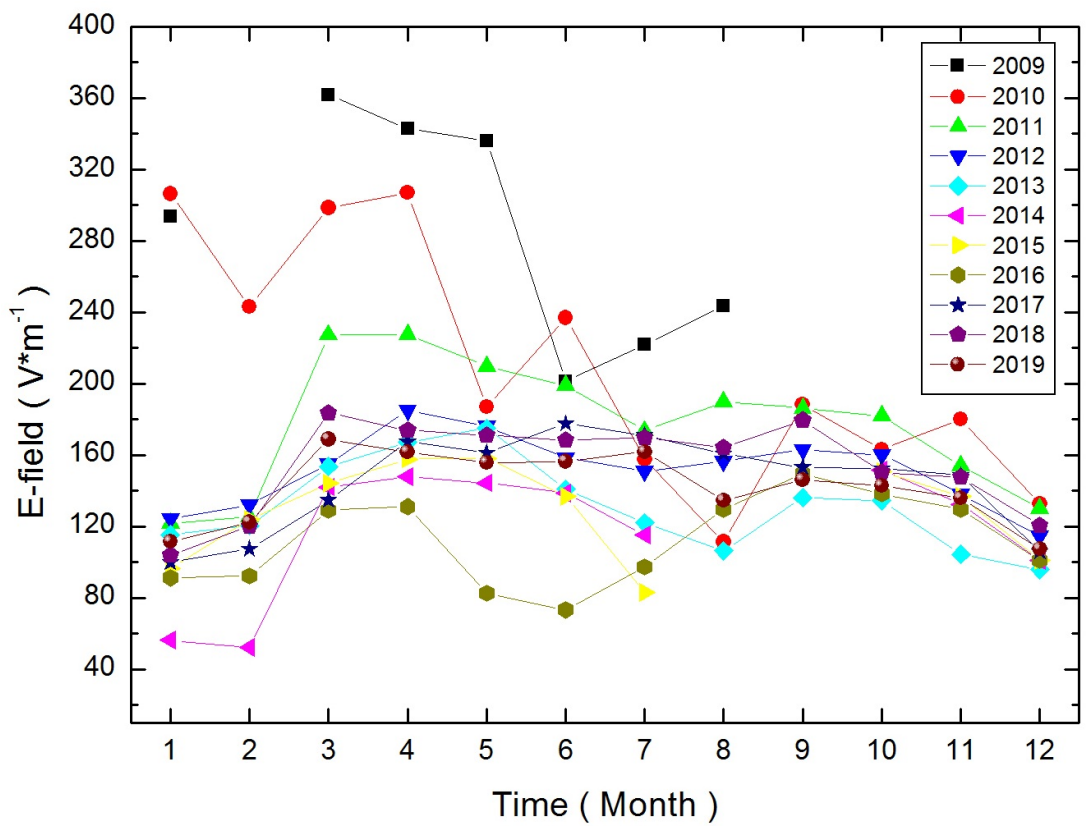

Fig. 1. Monthly mean values of atmospheric electric field in fair weather conditions for each year for the period from 2009 to 2019.

Figure 2 shows our main result from the analysis of atmospheric electric field data for 11 years of observations from January 2009 to December 2019.

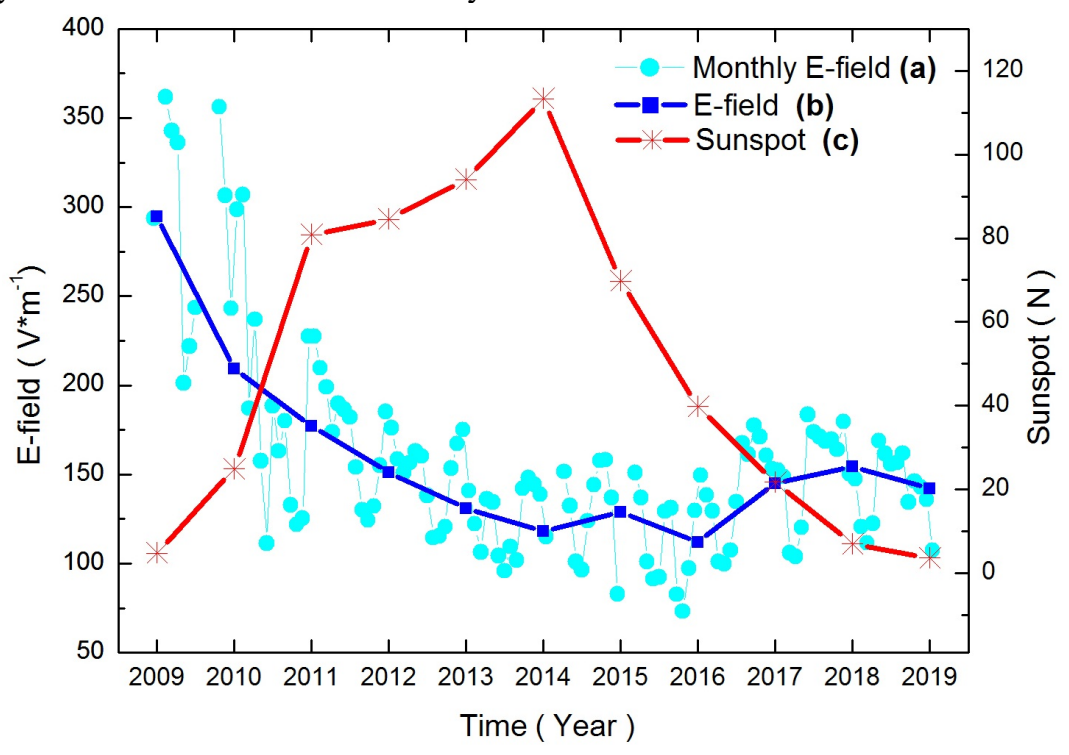

Fig. 2. Average annual values of the atmospheric electric field strength in the period from 2009 to 2019 (a). Average monthly values of the atmospheric electric field strength (b). The number of solar flares for the same period (c). 
One of the possible global causes of a planetary scale affecting the state of the atmospheric electric field as an element of the global electric circuit is solar activity, as shown in [7]

Figure 2 (b) clearly shows the change in the strength of the atmospheric electric field in antiphase to the number of flares in the sun. 2. (c). In addition, the field variations clearly show a trend towards a decrease in the average annual values of the field strength. A similar trend was described earlier in our work [8] and its presence is confirmed in new studies [9]. In order to clearly understand what effect solar activity has on the atmospheric electric field, it is necessary to continue continuous measurements in the next cycle of solar activity.

\section{Conclusions}

Analysis of the data on the strength of the atmospheric electric field in fair weather conditions showed that the seasonal variation of the monthly mean values of the field strength has maxima in the spring and autumn months and minimums in the summer and winter months. Annual variations in the field strength in fair weather conditions for the observation period from 2009 to 2019 change in antiphase to the level of solar activity (the number of solar flares) and have a general trend towards a decrease in the average annual field strength.

The study was supported by RFBR, research projects No. 18-45-140028 r_a.

\section{References}

1. Chalmers, J.A., Pergamon Press, Oxford. -1967.

2. Williams, Earle, and Eugene Mareev., Atmospheric Research 135 (2014): 208-227.

3. Rycroft, Michael J., et al., Planetary Atmospheric Electricity. Springer, New York, NY, 2008. 83-105.

4. Baishev, D. G., et al., Solar-Terrestrial Physics 3.2 (2017): 25-33.

5. Paramonov, N. A., Dokladi, Akademya Nauk USSR 71 (1950): 39-40.

6. Kozlov, V. I., Morozov, V. N., Nagorskiy, P. M., Pustovalov, K. N., \& Toropov, A. A., In 24th International Symposium on Atmospheric and Ocean Optics: Atmospheric Physics (2018, Vol. 10833, p. 1083380). International Society for Optics and Photonics.

7. Markson R., Bull. Am. Met. Soc., 2007. P. 223-241. Doi:10.1175 / BAMS-88-2-223.

8. Toropov, A. A., V. I. Kozlov, and R. R. Karimov., Nauka i obrazovanie 2 (2016): 58.

9. Tacza, J., Raulin, J.-P., Morales, C. A., Macotela, E., Marun, A., \& Fernandez, G., (2020) Atmospheric Research, 105200. doi:10.1016/j.atmosres.2020.105200. 